\title{
Desarrollo rural y deterioro del bosque. Región interestatal del Alto Lerma
}

\section{Rural development and forest deterioration in the interstate region of El Alto Lerma}

\author{
M aría Estela O rozco-H ernández* \\ Gabriela G utiérrez-M artínez* \\ Javier Delgado-Campos**
}

\begin{abstract}
This article analyses the natural and socioeconomic conditions of the interstate region of Alto Lerma through a diagnostic evaluation of the strengths, opportunities, weaknesses and threats that affect the usage of those areas that correspond to temperate forests. We provide some elements to re-think theforms of intervention and appropriation of the forest resources and propose strategies for the social and environmental support for rural communities. We have analysed cartographic, statistical and documental sources, as well as information obtained through interviews with government employees.
\end{abstract}

Keywords rural development, deterioration, forest, region.

\section{Resumen}

Esta investigación analiza las condiciones naturales y socioeconómicas de la región interestatal Alto Lerma, mediante una evaluación diagnóstica de las fortalezas, oportunidades, debilidades y amenazas que afectan la utilización de las áreas que corresponden a bosques templados. Se aportan elementos para repensar las formas de intervención y apropiación de los recursos forestales y se proponen estrategias para la atención social y ambiental de las comunidades rurales. Se analizó información cartográfica, estadística y documental, así como la obtenida por medio de entrevistas proporcionadas por funcionarios públicos.

Palabras clave: desarrollo rural, deterioro, bosque, región.

* Universidad Autónoma del Estado de M éxico. Correos-e: eorozcoh61@ hotmail. com,y lady_ponita03@yahoo.com.

** Universidad N acional Autónoma de M éxico. Correo-e: jdelgado@ igg.unam.mx. 


\section{Introducción}

En la óptica del desarrollo local endógeno se identifica al territorio como un actor que concede a cada comunidad la oportunidad de crecer con sus propios recursos, su saber hacer, su organización y sus valores (M artínez, 2001: 688). En el ámbito político los gobiernos locales y regionales son los protagonistas en la definición de las líneas sustantivas de la política económica (Alburquerque, 2001: 676). En consecuencia, las municipalidades tienden a operar como lugares de construcción democrática y de estrategias locales, estas últimas amplían o reducen las posibilidades de alcanzar el desarrollo (M éndez y Feijóo, 2001: 719).

En este sentido, el desarrollo local endógeno se concibe como una estrategia diseñada para mejorar el nivel de vida de grupos específicos de población, se ubica en la amplia dimensión de un proceso de transformación social que requiere replantear las relaciones con la naturaleza. Desde la perspectiva ambiental, el medio rural es el espacio idóneo para explicar los fenómenos y procesos multidimensionales de apropiación de los recursos naturales para gestionar el desarrollo (O rozco y Canales, 2007).

Es necesario entender la sustentabilidad como un proceso que debe surgir de las capacidades y conocimientos de los actores locales (Toledo y Bartra, 2000), mientras que el papel de los agentes externos debe consistir en reforzar los procesos de desarroIlo sustentable endógeno (Gerritsen et al., 2003: 273).

En el contexto sociopolítico actual las comunidades rurales desempeñan un papel fundamental en los ciclos de renovación y conservación de los recursos naturales, sin embargo, el deterioro de su forma de vida coloca en tela de juicio las políticas del desarrollo sustentable.

No obstante que el debate moderno sobre la sostenibilidad del desarrollo o desarrollo sustentable lo define como una dirección general de actuación que deja clara la necesidad de conservar los recursos y funciones naturales, y marca la importancia de al canzar objetivos sociales en lugar de objetivos individual es (Bermejo, 2000: 69, 72), la ausencia de mecanismos específicos para alcanzarlo lo convierten en una visión de futuro, si bien positiva, con limitaciones serias de viabilidad.

M éxico no es la excepción, la sustentabilidad se ha popularizado al hacerse parte del discurso económico, social y político actual. EI Plan N acional de Desarrollo 2007-2012 incorpora la sustentabilidad como eje transversal de las políticas públicas y 
Ios procesos de planeación (Gobierno Federal, 2007). En dicho plan el eje de la sustentabilidad ambiental contiene temas que denotan el dominio de la perspectiva conservacionista, la cual tiende a promover la compatibilidad entre la protección del ambiente y los procesos productivos. Así las cosas, el interés de la política nacional se centra en regular las consecuencias del deterioro ambiental y no las causas sociales, como el desempleo, la ausencia de oportunidades, la marginación social y la pobreza, asuntos que se tratan por separado en los ejes de economía competitiva y generadora de empleos e igualdad de oportunidades.

Lo anterior manifiesta que la sustentabilidad ambiental a la mexicana produce la separación funcional entre los fines de protección y conservación de los recursos naturales y el mejoramiento de las condiciones de vida de la población que los posee.

El interés por conservar y proteger los bosques y las selvas como aspectos estratégicos de la sustentabilidad ambiental, ha llevado a desarrollar estudios sobre la pérdida de la cubierta forestal y la deforestación; la importancia que ha adquirido el monitoreo y cuantificación de estos fenómenos para conseguir apoyos económicos, en $M$ éxico y el extranjero, minimiza el interés por analizar las causas del aprovechamiento de las cubiertas forestales con fines económicos, en el que están involucrados distintos agentes sociales que participan en los procesos de deterioro del bosque y de las áreas naturales, ${ }^{1}$ lo cual repercute de manera negativa en las condiciones de vida de la sociedad en general y muy especialmente de las poblaciones marginadas.

En M éxico los grandes biomas y tipos de vegetación ocupan una superficie de $151^{\prime} 483,194.5$ hectáreas, $22 \%$ de esta superficie (32'680,151.50 ha) se encuentra cubierta por bosque de coníferas, bosque mixto y bosque de encino: $24 \%$ de dicha superficie se asocia a vegetación secundaria como evidencia de su perturbación y deterioro, la cual es producto de la tala, la explotación de la vegetación original y la apertura de tierras al cultivo (Semarnat,

${ }^{1}$ La mayor parte de los estudios sobre deforestación se enfocan en la cuantificación del proceso, de aquí que se ha derivado una enorme cantidad de estimaciones sobre tasas de deforestación en el país, cuyos rangos fluctúan entre 350 mil y 960 mil hectáreas por año. Tal variación se debe tanto a la diversidad de tecnologías usadas en las estimaciones, como a las características de las regiones evaluadas; lo que sí es un hecho es que la tasa de deforestación es muy elevada. El problema de deforestación se agrava en las selvas, mientras que los bosques de zonas de montaña y de las regiones áridas y semiáridas son afectados principalmente por la degradación, que a final de cuentas es sólo una etapa anterior a la deforestación. El problema se observa con mayor intensidad en áreas forestales que no están bajo un manejo sistemático o bien donde los usos no maderables son escasos, incluyendo las áreas naturales protegidas (INE, 2000). 
2003). En este contexto, los ecosistemas de bosque templado son los menos conservados del país, se estima que se ha perdido entre $50 \%$ y $67 \%$ de la superficie original (Challenger, 2004).

La unidad espacial que nos interesa y que denominamos región interestatal del Alto Lerma (RIAL) comprende los estados de Q uerétaro, M éxico, Guanajuato y M ichoacán, ${ }^{2}$ mismos que pertenecen a las regiones geoeconómicas centro-este y centro-occidente (Bassols, 1983: 394). Se consideran 128 municipios que forman parte total o parcialmente de las cuencas de los ríos Lerma y Balsas, los cuales se integraron en ocho subregiones: Bajío de Guanajuato-Celaya, noreste del Estado de M éxico, sureste del Estado de M éxico, Toluca-Lerma, Valle de Bravo, Bajío de M ichoacán, noreste de M ichoacán y San Juan del Río.

La RIAL tiene una extensión de 37'948,724 km² $(2.3 \%$ del territorio nacional), $25 \%$ de la superficie está cubierta por bosque templado y $41 \%$ corresponde a tierras de uso agrícola y pecuario, estos datos permiten plantear que la pérdida y deterioro del bosque constituyen una consecuencia de las acciones y decisiones de los distintos actores sociales que participan en el aprovechamiento del suelo y el bosque con fines económicos.

\section{M etodología}

En la caracterización de la región se utilizó cartografía temática escala 1:50,000 y 1:250,000 (climática, edafológica, geológica, agua superficial y subterránea, uso del suelo y frontera agrícola), también se analizó información estadística de los censos de población, agropecuarios, económicos y la literatura disponible. A partir de la caracterización natural y socioeconómica se identificaron las fortalezas, oportunidades, debilidades y amenazas de la región (FODA) y se obtuvieron los elementos para diseñar políticas y estrategias acordes con la perspectiva del desarrollo rural.

\section{Contexto interestatal}

La superficie forestal de M ichoacán, Estado de M éxico, Guanajuato y Q uerétaro representa 2.2\% (3'327,467 ha) de la superficie forestal nacional y $8 \%\left(2^{\prime} 673,392\right.$ ha) de la superficie de

\footnotetext{
${ }^{2}$ La región no es una unidad geográfica arbitraria, se genera a partir de un sistema de relaciones de producción, que a su vez determinan el comportamiento económicosocial. Comparte elementos con la escala local y nacional, pero es necesario encontrar sus especificidades diferenciales (Rofman, 1993).
} 
bosque templado. M ichoacán y Guanajuato tienen la mayor superficie forestal, $78.2 \%$ y $12.4 \%$, respectivamente. M ichoacán cuenta con $58 \%$ y el Estado de M éxico con $21 \%$ de la superficie de bosque (Semarnat, 2003). Las áreas perturbadas ocupan $27 \%$ de la superficie forestal regional y M ichoacán concentra $74 \%$ de dicha superficie (figura 1 ).

N o obstante que la perturbación del bosque como paso previo de la deforestación y que el cambio de uso del suelo se atribuye en términos generales al avance de la frontera agrícola, la situación tiene raíces mucho más profundas, que tienen que ver con coyunturas histórico-políticas de larga duración, entre ellas, el proceso de reparto agrario iniciado en la primera mitad del siglo xx. H asta 1992, año que marca el fin del reparto agrario, el aumento de la frontera agrícola estaba vinculado en buena medida con la creación de nuevos núcleos ejidales, muchos de ellos formados por hijos de ejidatarios o campesinos sin tierra en busca de nuevas dotaciones. Esto lo posibilitó una política explícita de desmonte junto con una política de colonización de territorios con baja densidad poblacional (INE, 2000: 11), así como una política de apoyo al desarrollo de las actividades agropecuarias y el fomento a la explotación forestal basada, hasta 1980, en concesiones otorgadas a compañías privadas y paraestatales para explotar los bosques de alta calidad (G-Bosques, 2006).

En el ámbito de las comunidades rurales, las prácticas socioculturales de aprovechamiento y manejo de la tierra han jugado un papel fundamental en la conservación y/o deterioro de la cubierta forestal. Por ejemplo, la quema de la vegetación ${ }^{3}$ que cada ciclo agrícola realizan los ejidatarios y comuneros favorece el rebrote de pasto tierno para alimentar el ganado y la germinación de las semillas de algunas especies de árboles; sin embargo, su finalidad última es el desmonte para abrir más tierras al cultivo y a la ganadería.

Tanto la quema como la apertura de tierras al cultivo tienen una doble connotación, por un lado, se puede ver la persistencia de una estrategia de supervivencia campesina y, por el otro, una forma depredadora del bosque y el entorno natural. En esta doble perspectiva, resulta paradójico que las actividades agropecuarias

\footnotetext{
${ }^{3}$ A pesar de que a partir de 1998 se hizo más estricto el calendario de quemas controladas y ha tenido mayor difusión el uso de prácticas más seguras para su ejecución, todavía el causal de incendio más importante sigue siendo el escape y falta de control de incendios agropecuarios (INE, 2000).
} 
Figura I

\section{Superficie forestal y tipo de ecosistema}

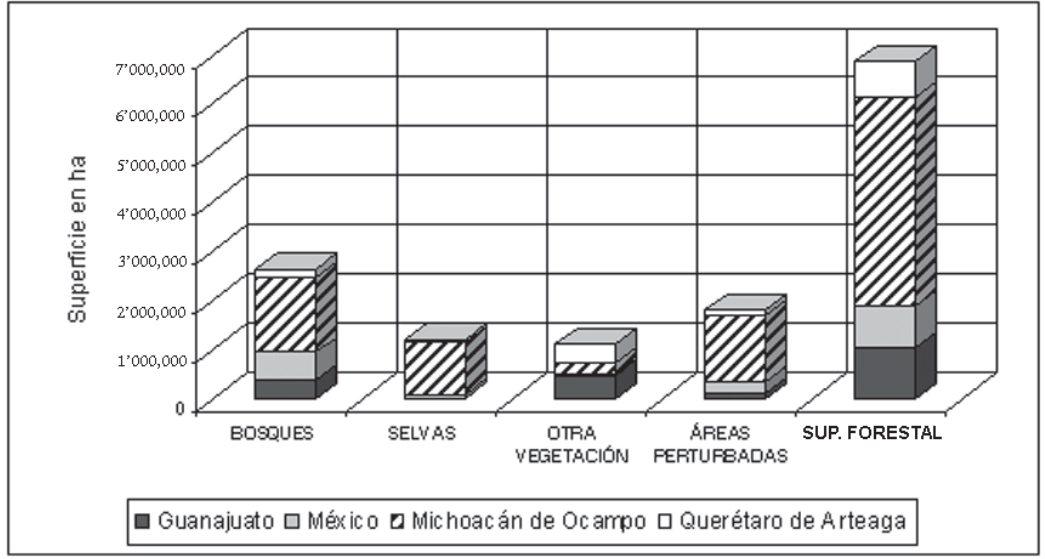

Fuente: Semarnat (2003), Compendio de Estadísticas Ambientales 2002, M éxico, D.F.

Figura II

Incendios forestales por entidad federativa 1970-2005

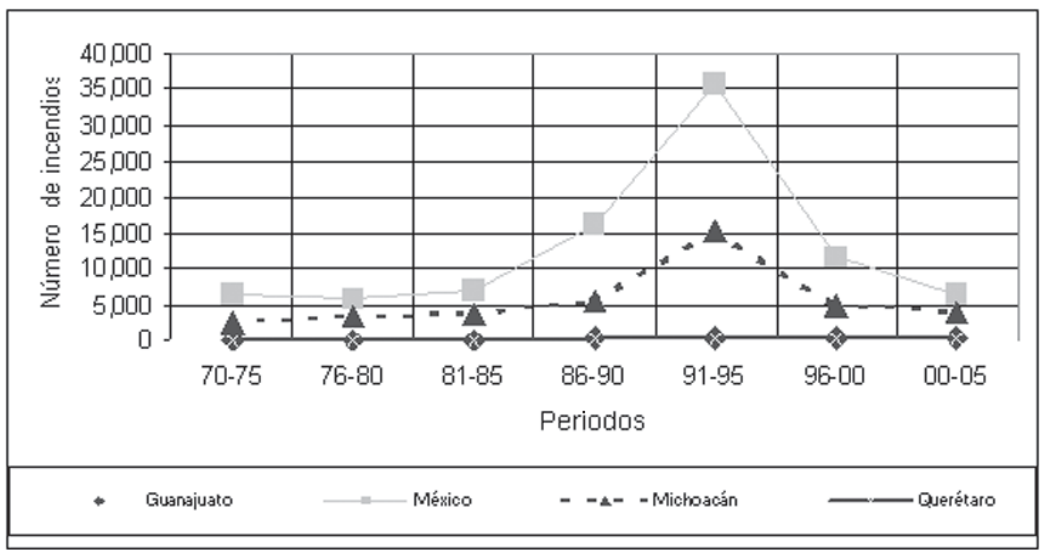

Fuente: Conafor, 2006. 
ocupen el primer lugar como causa ${ }^{4}$ de la propagación libre del fuego sobre la vegetación natural (incendio forestal). Esta práctica ancestral se realiza empíricamente sin tomar en cuenta el riesgo de la expansión del fuego más allá de lo previsto. Año con año se inducen miles de pequeños fuegos, los cuales no alcanzan la denominación de incendios forestal es porque los terrenos afectados no representan grandes superficies (Semarnap, 1998).

Los datos sobre los incendios en el periodo 1970 a 2005 no son alentadores, destaca el quinquenio 1991-1995 con el mayor número de siniestros provocados por la quema de la cubierta forestal para abrir tierras al cultivo y la ganadería, particularmente en los estados de M éxico y M ichoacán ${ }^{5}$ (Conafor, 2005; figura ॥).

La superficie afectada por los incendios incluye las áreas quemadas y aquellas que han sufrido alguna alteración, el daño provocado por los siniestros no sólo incrementa los costos de las actividades correctivas de combate a los incendios, sino que reduce rápidamente la superficie forestal y atenta contra los bienes y servicios ecológicos que proveen los bosques (purificación de oxígeno, hábitat de fauna silvestre, captación de agua de lluvia, recarga de los mantos acuíferos y contención de la erosión del suelo).

0 tro factor de alteración de la cubierta forestal es la extracción de madera y resina con fines comerciales e industriales. Los estados de M éxico y M ichoacán ocupan los primeros lugares en las estadísticas oficiales como productores de estos recursos (Ramírez, 2001: 39). Salvo en algunos lugares de M ichoacán en los que se hace la resinación de los árboles de pino con base en la norma N O M -026, donde se establecen las especificaciones técnicas para realizar está actividad (DOF, 2006), en la mayoría de las comunidades, en especial las del Estado de M éxico, la resinación se realiza como una actividad de subsistencia en condiciones técnicas rudimentarias que deterioran los árboles y los hace más susceptibles a las plagas y al fuego.

La tala ilegal del bosque funge como un factor de presión hormiga, que nadie ve, pero todos saben que existe. Debido a su ilegalidad no se ha cuantificado su participación en la devasta-

${ }^{4}$ Las causas más frecuentes de los incendios forestales son: actividades agropecuarias $(48 \%)$, incendios provocados $(17 \%)$, fogatas $(16 \%)$, fumadores $(8 \%)$, actividad silvícola (3\%), derechos de vía (1\%), otras actividades productivas (1\%), otras causas (6\%) (Semarnap, 2000).

${ }^{5}$ En M ichoacán cada año resultan afectadas 40 mil hectáreas a causa de la deforestación y los incendios, en contraparte, anualmente son reforestadas 15 mil hectáreas, pero la efectividad de las plantaciones es de sólo $60 \%$. Así, en forma definitiva se pierden 31 mil hectáreas de bosque en ese lapso (Conafor, 2005). 
ción del bosque en zonas de difícil acceso y en áreas naturales protegidas. En el Estado de M éxico cuatro zonas son críticas por los ilícitos forestales: Sierra de las Cruces, Reserva Forestal las Goletas, N evado de Toluca y la Reserva de la Biosfera M ariposa M onarca, este último caso lo comparte con M ichoacán.

La miseria, la falta de alternativas de trabajo para los habitantes y la inaccesibilidad física de las zonas forestales promueven las talas ilegales para obtener madera o leña para uso doméstico, así como la formación de grupos organizados cuya actividad principal es el aprovechamiento ilegal de madera y el comercio clandestino, lo cual se sobrepone en varios casos al tráfico de estupefacientes. Al respecto se estima que el aprovechamiento de las cortas legales, ilegales y desmontes sobrepasa el incremento natural, aproximadamente la mitad de la remoción maderable es ilegal o no autorizada/registrada (INE, 2000: 10, 13).

De acuerdo con la información oficial, los sectores agricultura, ganadería, aprovechamiento forestal, pesca y caza incluyen al subsector forestal (INEGI, 2004), lo cual no permite discernir qué papel juega la fase de explotación del bosque en el proceso económico. Barton y M erino (2004: 1-26) describen el declive de la producción comercial de madera desde 1987 y su participación de menos de $1 \%$ al PIB nacional a comienzos de los años noventa. El declive se explica por la poca o nula inversión en la fase primaria de la producción forestal maderable y por el limitado acceso al crédito en terrenos forestales de uso común; resulta prácticamente imposible gravar una porción o la totalidad de un terreno asentado dentro de un núcleo agrario, incluso, no es posible gravar el suelo (masa forestal cosechable) de terrenos comunales, dado que la cosecha maderable tiene restricciones muy importantes (INE, 2000: 9).

En la fase de transformación de la madera sobresale el subsector 321, el cual reporta para la región 5,367 unidades económicas, las entidades de M éxico y M ichoacán participan con $27 \%$ y $50 \%$ de estas unidades, aportan 33\% y $50 \%$ del personal ocupado, cada una $42 \%$ de las remuneraciones totales, $40 \%$ y $48 \%$ de la producción bruta total, $40 \%$ y $44 \%$ del valor agregado censal bruto y $50 \%$ y $41 \%$ del total de activos fijos, todo esto respectivamente.

La deficiente competitividad de la industria maderera se manifiesta en la rama del aserrado y conservación de la madera, misma que presenta bajos niveles de inversión, tecnología obsoleta, baja derrama de empleo y falta de integración del proceso productivo. La situación se atribuye a los bajos niveles de inver- 
sión -que se estiman por debajo de 4\% del presupuesto destinado para la agricultura-, que aunado a los altos costos de producción hacen de la industria forestal un sector poco competitivo (M orán y Galletti, 2002).

La baja competitividad del sector forestal ${ }^{6}$ se explica por los altos costos de extracción y el transporte, estimados en $46 \%$ de los costos totales, mientras que las actividades relacionadas con el manejo forestal no cubren ni $2 \%$ del costo total, es decir, los elevados costos de extracción reducen notablemente la rentabilidad de la actividad forestal en los núcleos agrarios, lo cual no permite mejorar la capacidad técnica, la organización y la calificación de la fuerza de trabajo local (INE, 2000: 20).

En términos generales, la producción y la transformación forestal juegan un papel menor en la economía nacional, sin embargo, en las economías estatales tiene relativa importancia por su contribución al producto interno bruto, en los estados de M éxico, M ichoacán, Guanajuato y Q uerétaro aporta 4.4\%, 7.6\%, $1.7 \%$ y $3.3 \%$, respectivamente (INEGI, 1997).

La contribución económica del subsector forestal y la superficie sujeta a protección (ANP) en las entidades consideradas en este estudio, las han ubicado en los programas de reforestación. En los últimos nueve años, en el país se han reforestado 1'327,030 hectáreas, Guanajuato, Estado de M éxico, M ichoacán y Querétaro participan con $26 \%$ de la superficie nacional reforestada (Semarnat, 2003), sin embargo, las acciones han sido insuficientes ya que la superficie reforestada representa solamente $4 \%$ de las áreas perturbadas de dichas entidades.

\section{Diversidad natural y social}

La dinámica poblacional y el desarrollo agrícola e industrial de la región se sostienen en el agua que aportan los ríos, lagos y presas, aproximadamente $24.7 \%$ de la superficie regional está ocupada por cuerpos de agua $7\left(8,728.21 \mathrm{~km}^{2}\right)$. La composición de la

${ }^{6}$ En M éxico el subsector forestal sólo contribuye con 3.6\% del producto bruto industrial, es decir, menos de $1 \%$ del producto interno bruto. Sostiene un poco más de 300,000 plazas de empleo y la balanza comercial del sector es deficitaria (M orán y Galletti, 2002).

${ }^{7}$ El porcentaje estimado para este uso se obtuvo mediante la suma total de la superficie de los cuerpos de agua registrados en la base de datos de la CNA, monografías y planes de desarrollo municipales y estatales $\left(\mathrm{km}^{2}\right)$. 
población se estableció de la siguiente manera: urbana (42.1\%), rural $(45.3 \%),{ }^{8}$ mixta (10\%) y en transición (2.6\%) (cuadro 1 ).

La ocupación territorial se caracteriza por un patrón de zonas dispersas y poco pobladas, mientras que la población urbana se concentra en pequeños y medianos subcentros regionales. ${ }^{9} \mathrm{EI}$ espacio urbano denota el surgimiento de áreas suburbanas y en proceso de consolidación, cuya existencia responde a la inmigración de población rural para acceder a la oferta de trabajo y al bajo precio de los terrenos para ser habitados en áreas con servicios limitados o ausentes.

En el ámbito regional, $4.1 \%$ de la población de cinco años y más habla alguna lengua indígena (otomí, náhuatl, purépecha, maya, mazahua, mixteco y otros), la presencia de población indígena es un rasgo característico del noreste del Estado de M éxico-Atlacomulco y Toluca-Lerma.

El 16\% de la población de 15 años y más es analfabeta, su distribución municipal es heterogénea, ello depende de la disponibilidad de infraestructura y servicios para la educación, de la existencia de hablantes de lengua indígena y del acceso a los centros y subcentros urbanos, como ejemplos contrastantes, la subregión Toluca-Lerma presenta una tasa de alfabetismo superior a $90 \%$, y las subregiones de Valle de Bravo y el sur del Estado de M éxico ostentan los más altos índices de analfabetismo, superiores a $20 \%$.

La población mayor de 12 años que tiene las condiciones físicas para ejercer un trabajo productivo (PEA) constituye $26 \%$ (1'855,042) de la población total regional. El 98.7\% de esta población se reporta como ocupada (INEGI, 2000).

A pesar de que la tasa de desempleo es baja (1.3\%), la mayor parte de la PEA se dedica a las actividades terciarias (56\%) por cuenta propia, el sector secundario es la segunda fuente de empleo (27\%) y el sector primario ocupa a $17 \%$ de la peA total (figura III).

La terciarización de la economía se corresponde con una disminución del empleo y la fragmentación del ingreso. El 18\% de la población ocupada no recibe ingresos, $15 \%$ vive con menos de

${ }^{8}$ Luis Unikel (1978) clasifica las localidades como rural, mixta rural, mixta urbana y urbana; donde las rurales son las que tiene menos de 5,000 habitantes, las mixtas rurales son aquellas cuyo número de habitantes va de más de 5,000 a 10,000, las mixtas urbanas de más de 10,000 a 15,000 y las urbanas son las que superan los 15,000 habitantes.

${ }^{9}$ Ciudades de Toluca, Atlacomulco, Zinacantepec, Lerma, O coyoacac, M etepec, N icolás Romero, San M ateo Atenco, Santiago Tianguistenco, O coyoacac, Celaya, Acámbaro, A paseo el Grande, Salvatierra, Uriangato, Villagrán, Yuriria, Cortázar, M oroleón, Zitácuaro, La Piedad, H idalgo, M aravatío, San Juan del Río y Tequisquiapan. 


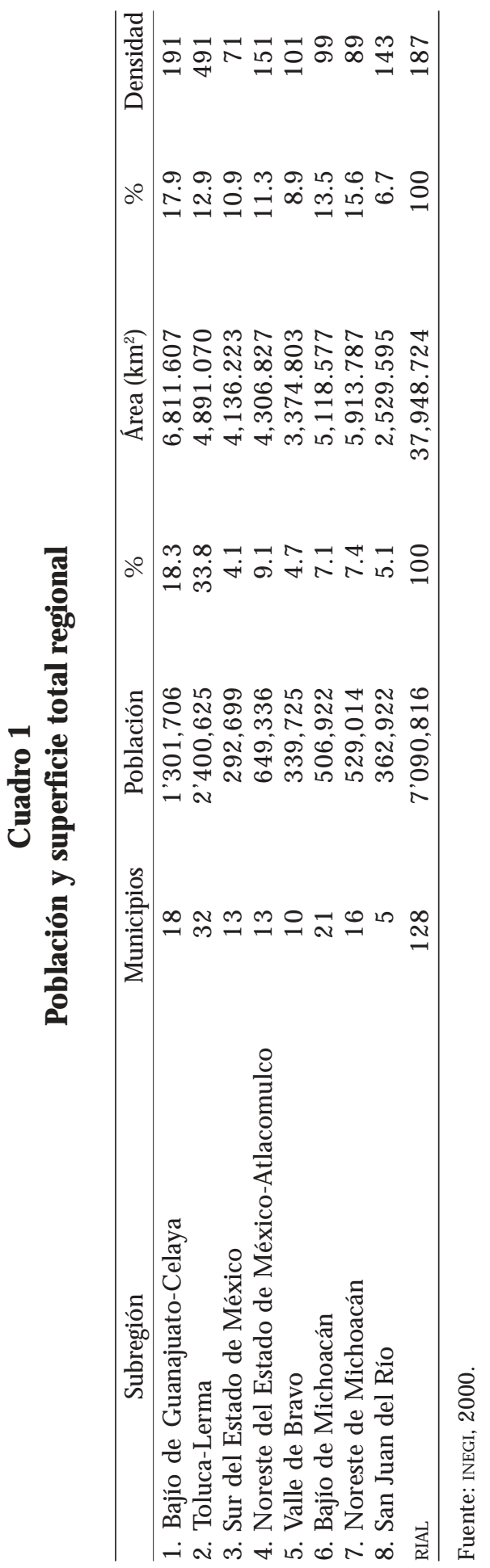




\section{Figura III \\ Fragmentación del ingreso}

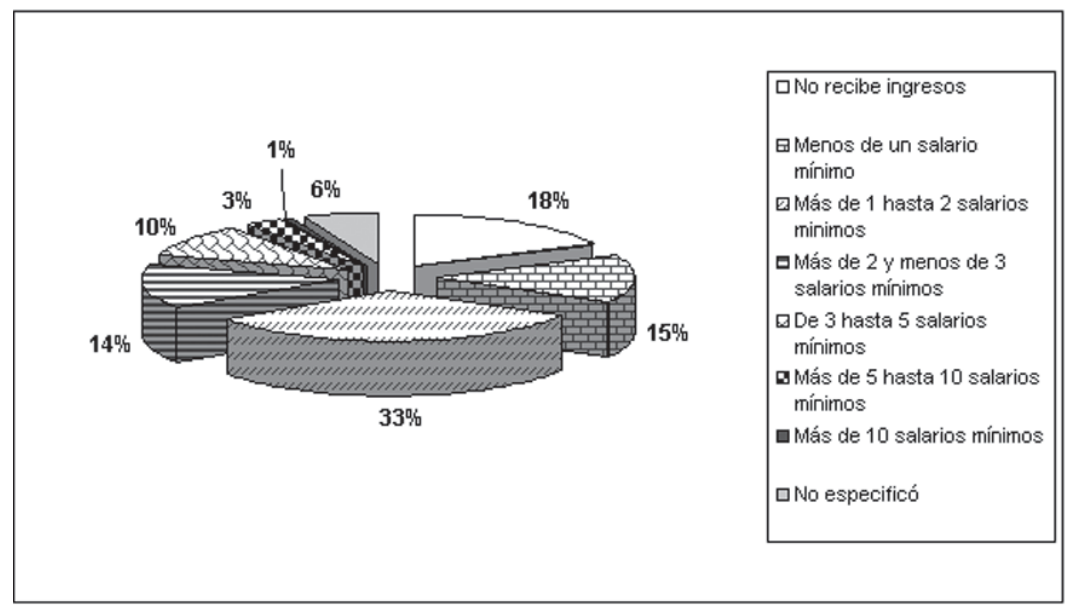

Fuente: INEGI, 2000.

un salario mínimo y $47 \%$ con más de uno y hasta tres salarios, es decir, $80 \%$ de la población ocupada y sus familiares viven con salarios de supervivencia

La Encuesta $\mathrm{N}$ acional de Alimentación y $\mathrm{N}$ utrición en el M edio Rural reporta que las familias rurales invirtieron por arriba de 40 pesos a la semana per cápita en la compra exclusivamente de alimentos (Ávila et al., 2005: 19). El número de integrantes promedio por familia, es cinco, ${ }^{10}$ por lo tanto, el gasto semanal por la compra de alimentos asciende a 200 pesos. Para el año de referencia, el salario mínimo diario promedio estaba fijado en $\mathbf{4 5 . 2}$ pesos (STPS, 2005) o 226 pesos por semana. La diferencia entre lo que se invirtió en alimentos y se recibió, es mínima. Se supone que el ingreso sobrante debería cumplir con la satisfacción de otras necesidades básicas, como el vestido, la educación y la salud, pero sólo se contaba con 26 pesos o menos de tres dólares para satisfacer estas necesidades.

El deterioro del ingreso, la marginación social y la pobreza son rasgos que matizan las condiciones de desarrollo de las economías estatales, pero en la medida que se trasminan a los mi-

${ }^{10}$ En la encuesta de referencia, la base de la muestra fueron 2,364 familias y se registraron 12,437 integrantes, con los datos se estimó el número de integrantes promedio por familia (5.2 personas). Adicionalmente, es posible afirmar que en el periodo 2005-2009, el incremento del salario mínimo promedio diario ha sido sólo de 8.1 pesos (Comisión Nacional de Salarios M ínimos. http://www.conasami.gob.mx/, consulta 5 de febrero de 2009). 
croespacios de las comunidades rurales en las que se realiza la explotación forestal, se convierten en factores estructurales que producen efectos funcionales que impiden el uso eficiente de los recursos naturales, la urgencia de cubrir las necesidades básicas lleva a los poseedores del bosque a tomar decisiones de aprovechamiento y consumo inconvenientes, lo que perpetúa el deterioro de sus condiciones de vida y de los recursos naturales con los que cuentan. ${ }^{11}$

La tesis de la relación causa-efecto entre la pobreza-deterioro y el manejo-conservación permite precisar que a mayor pobreza de las comunidades rurales, más incremento de la deforestación en zonas marginadas y muy marginadas, lo cual se debe a la tala ilegal y la mayor dependencia de madera para energía y consumo doméstico. En tanto que a mayor actividad de manejo forestal, menor deforestación y menos incidencia de incendios, lo que significa que las comunidades conservan el bosque en la medida que les proporciona satisfactores en el corto plazo (INE, 2000: 15-17).

Los escenarios antes delineados exponen que el mejoramiento de las condiciones de vida de la población que habita las comunidades y el alivio a la degradación forestal no dependen sólo del incremento del ingreso, sino que está fuertemente determinado por las posibilidades de pervivencia a futuro, en las que la disponibilidad y el manejo adecuado de los recursos naturales son aspectos de vital importancia para ampliar las posibilidades de desarrollo humano. ${ }^{12}$

D esde esta perspectiva, el entorno natural resultado de la interrelación de factores bióticos y abióticos, se constituye en una plataforma básica para impulsar el desarrollo de las comunidades rurales forestales, proporciona gran diversidad florística y ecológica que dota a la región de una variada y rica superficie

${ }^{11}$ Yuriria, Acambay, Chapa de M ota, Jocotitlán, San Felipe del Progreso, Temascaltepec, Tlatlaya, Tenancingo, Tenango del Valle, Tianguistenco, Amanalco, D onato Guerra, Ixtapan del Oro, Valle de Bravo, M orelos, Queréndaro, Zinapécuaro, Aporo, $\mathrm{H}$ idalgo, O campo, Senguio, Susupuato y Tuzantla.

${ }^{12}$ El desarrollo humano es la ampliación de las posibilidades de los individuos para elegir. Tres de las capacidades fundamentales para la realización del potencial humano, independientemente del tiempo y el lugar en que se ubiquen las personas, son la posibilidad de alcanzar una vida larga y saludable, adquirir conocimientos individual y socialmente valiosos, y tener la oportunidad de obtener los recursos necesarios para disfrutar de un nivel de vida decoroso. Sin embargo, ya sea en su sentido como situación o como cambio, el desarrollo humano se refiere al conjunto de oportunidades de valor para las personas, sean éstas políticas, económicas o sociales, ya sea para la supervivencia, la autoestima, la superación personal, el trabajo, la creatividad, la integración social o el ejercicio del poder (PNUD, 2003). 
forestal (bosque, zonas selváticas, alternándose con matorrales y pastizales). En el país el componente endémico de los bosques es alto, es el centro de diversidad mundial de pinos con $50 \%$ de las especies conocidas y el centro de diversidad hemisférica para encinos, con 33\% del total mundial (Challenger, 2004).

El bosque templado prospera en áreas montañosas templadas y semifrías, se tienen variantes de pino y encino, bosques mixtos y bosques de coníferas que albergan gran variedad de vida silvestre (mamíferos, aves, reptiles e invertebrados) (cuadro 2).

La distribución de los macizos de bosque en el centro de M éxico, en su mayor parte coincide con la provincia fisiográfica del Sistema Volcánico Transversal, se localizan en altitudes de 1,200 a 3,600 msnm, en áreas cuya precipitación y temperatura media anual oscila entre 350 y $1,200 \mathrm{~mm}$ y $6^{\circ}$ y $28^{\circ} \mathrm{C}$, respectivamente (Rzedowsky, 1983: 285-286). En altitudes superiores a 2,500 msnm se encuentra el bosque puro de pinos (noreste de M ichoacán, sur del Estado de M éxico, Valle de Bravo y TolucaLerma). El aprovechamiento de la cubierta forestal para las actividades agropecuarias, los incendios periódicos y el pastoreo desordenado, así como la explotación comercial del bosque y el aprovechamiento doméstico de la leña han ocasionado el desarrollo secundario de manchones aislados de bosque y la disminución de la superficie forestal.

La situación descrita identifica dos tendencias principales: una que confirma el impacto histórico ocasionado por el desmonte de áreas extensas de bosque para uso agrícola y la extracción legal e ilegal de madera para usos comercial, industrial y doméstico; la segunda tendencia muestra la importancia del bosque como reservorio de ricas áreas de flora y fauna, mismas que han sido protegidas con diferentes decretos que establecen su conservación, aprovechamiento y restauración.

En la región las áreas naturales protegidas (AN P) ocupan 47.3\% de la superficie forestal, las más importantes son: la R eserva Especial de la Biosfera $\mathrm{M}$ ariposa $\mathrm{M}$ onarca, los parques nacionales del N evado de Toluca, M iguel H idalgo y Costilla (La M arquesa), Bosencheve y Desierto del Carmen, así como las áreas de protección de flora y fauna de las Ciénegas del Lerma (Conanp, 2005).

El caso emblemático de la Reserva de la Biosfera de la M ariposa M onarca (RBM M ) se evidenció en el periodo 1984-1999 con la degradación de $44 \%$ de la superficie ocupada por bosques de alta calidad provocada por la explotación incontrolada (WWF, 2004). A partir del año 2000 se implementa una serie de medidas 


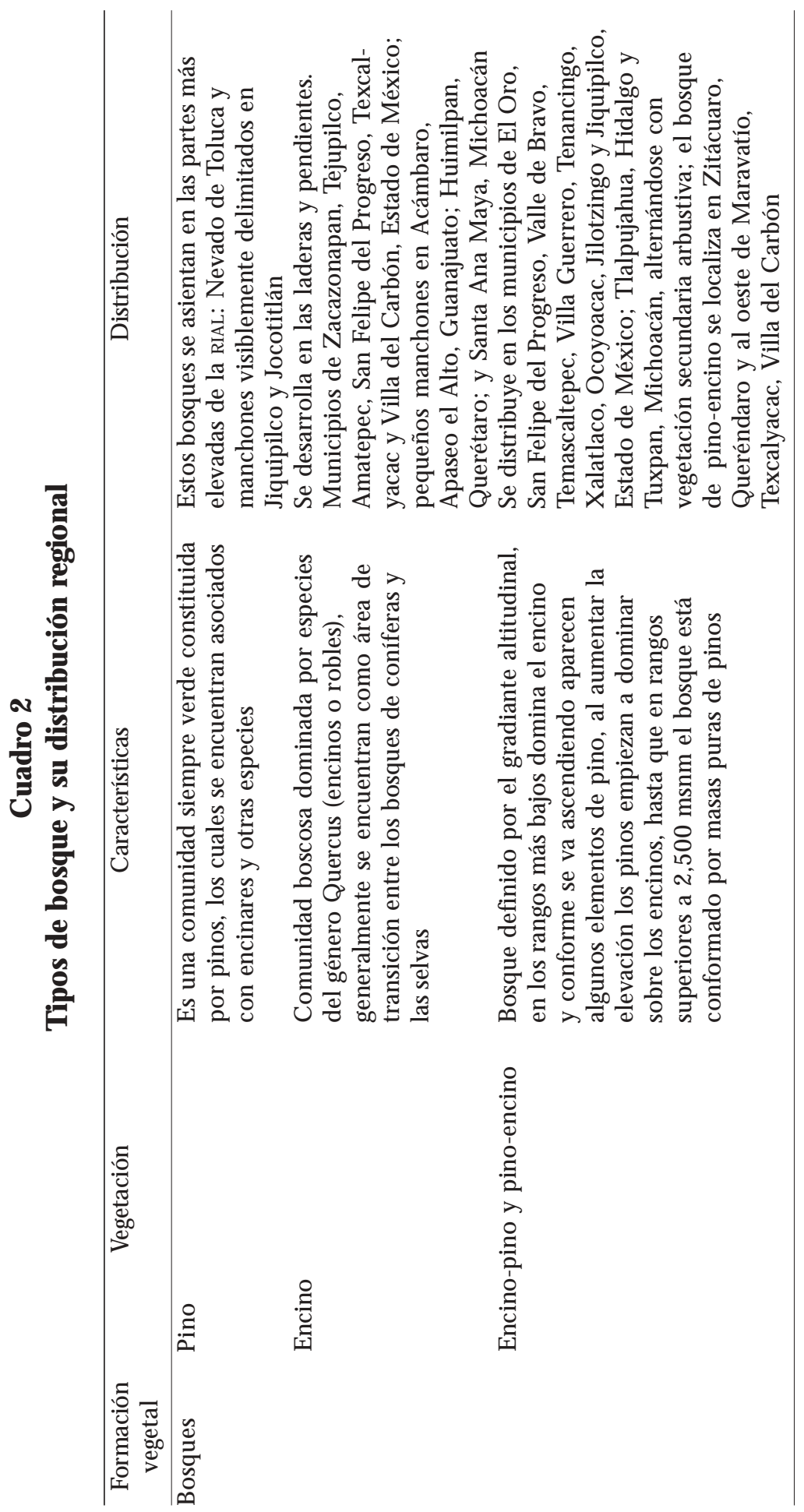




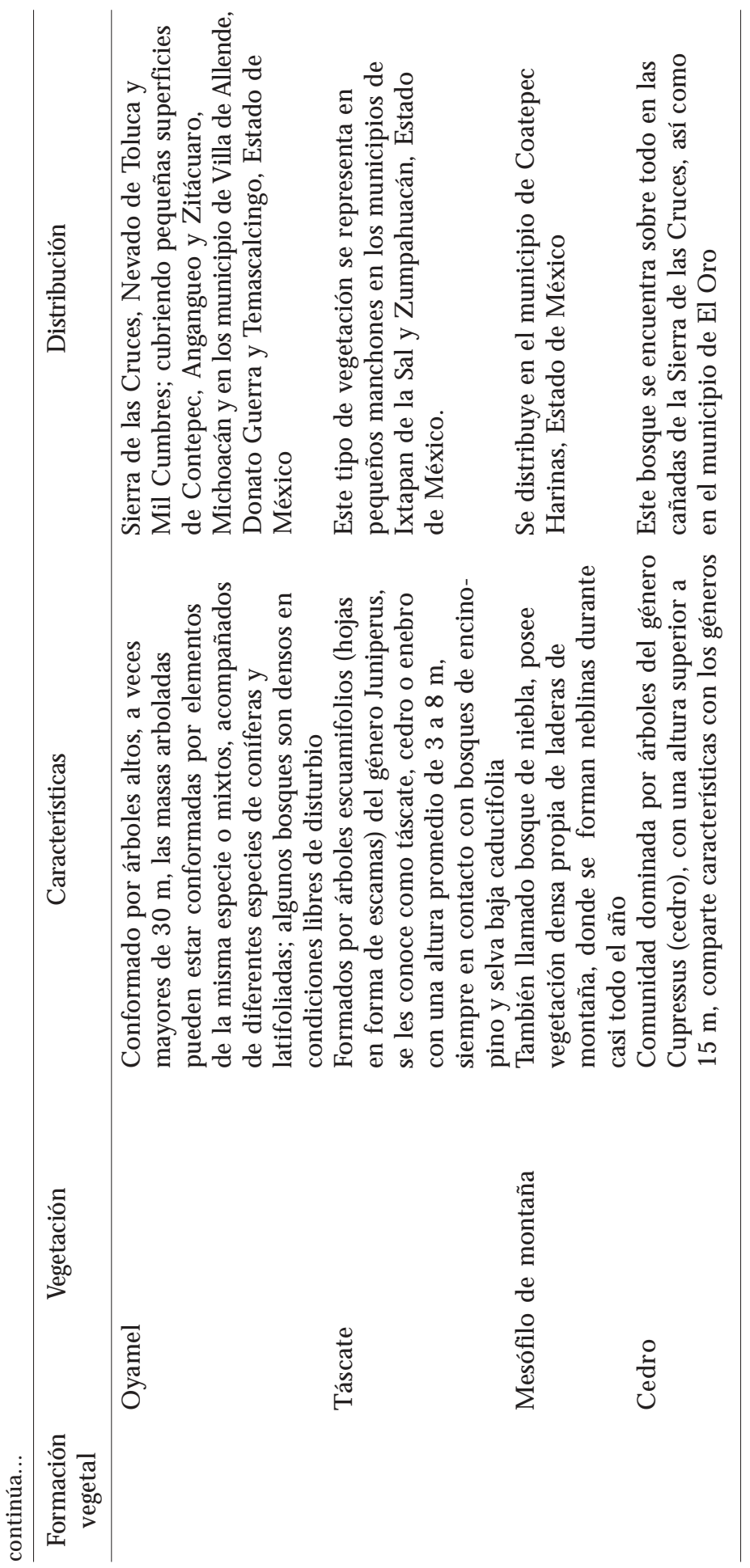




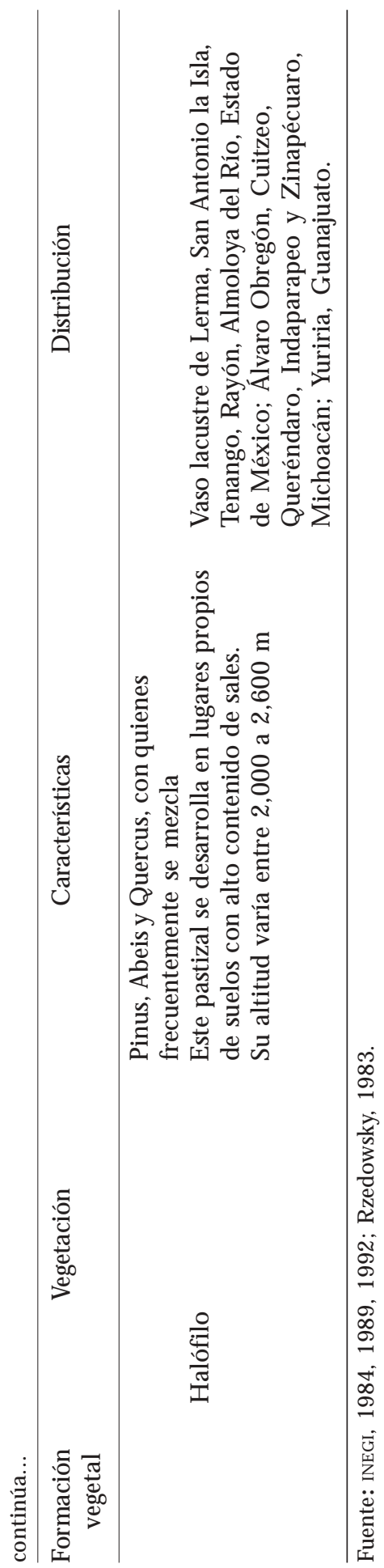


económicas, como los fondos para el pago por servicios ambientales, sin embargo, la cobertura y efectividad de los pagos es limitada frente a una política forestal que ha incrementado las restricciones del aprovechamiento del bosque.

La gama de programas orientados al sector forestal que comienza a operar en los años noventa ${ }^{13}$ bajo la tutela de la Semarnat, han mostrado problemas para el desarrollo de esquemas de producción forestal y conservación del bosque. En muchos casos la falta de seguimiento, el no contar con una estimación real de la demanda de productos, así como la falta de organización para la producción han resultado en muy buenas intenciones pero con poca eficiencia (INE, 2000: 14). El antagonismo que se produce entre la reciente política de desarrollo forestal sustentable y la política agropecuaria se manifiesta en los incentivos que se otorgan para el fomento del cultivo de la tierra y el consecuente incremento de la deforestación. ${ }^{14}$ Los efectos que producen los subsidios acoplados ${ }^{15}$ a la producción agrícola se manifiestan en la distorsión del mercado y en costos el evados de los productos; y por el lado del desarrollo sostenible, los incentivos provocan una mayor expansión de la actividad económica sobre áreas naturales o una mayor descarga de contaminantes, es decir, los subsidios que afectan el comercio interno o internacional son una situación de doble pérdida, económica y ambiental, aunque para los grupos que los reciben sí sean transferencias positivas reales (M uñoz, 2004: 1). En la actualidad, la Ley de Desarrollo Forestal Sustentable (DoF, 2003), la modificación del Artículo 27 Constitucional y la Ley Agraria dotan a los ejidos y comunidades agrarias de la libertad de organizarse y aprovechar sus recursos forestales con autonomía, sin embargo, se mantiene un alto nivel de control por parte del gobierno federal mediante los lineamien-

${ }^{13}$ Programa de Desarrollo Forestal (Prodefor), Programa de Plantaciones Forestales (Prodeplan), Programa N acional de Reforestación (Pronare), Programas de Desarrollo Regional Sustentable (Proders), Programa de Conservación y M anejo Sustentable de Recursos Forestales (Procymaf), Programa de Empleo Temporal (PET), en su vertiente ambiental (INE, 2000).

${ }^{14}$ Cada año se pierden alrededor de 600 mil hectáreas de bosques y selvas en M éxico (G-Bosques, 2006: 70).

${ }^{15}$ Comercialización y Alianza para el Campo, como parte del Acuerdo $\mathrm{N}$ acional por el Campo 2, tienen un presupuesto de más de doce mil millones de pesos, cerca del doble de lo asignado mediante el rubro de subsidios más desacoplados, que es Procampo. Además de estos dos programas, también causan distorsiones en los mercados tres tipos de intervenciones gubernamentales: 1) la exención al impuesto al valor agregado (IVA) para fertilizantes plaguicidas y otros agroquímicos, 2) el subsidio al diesel para uso agrícola, y 3) el subsidio en las tarifas de electricidad para el bombeo de agua de riego (M uñoz, 2004: 3). 
tos restrictivos que limitan los derechos de propiedad y el uso de los recursos forestales por parte de las comunidades rurales, en especial en las áreas naturales protegidas. ${ }^{16}$

Aun cuando las acciones de intervención del gobierno federal se inscriben en la línea del desarrollo sustentable para el fomento directo a la conservación o buen manejo de las áreas forestales, todavía no se ha logrado vislumbrar una política coherente que vincule la conservación y mantenimiento de los bosques con el desarrollo social de las comunidades forestales.

\section{Propiedad social y aprovechamiento del bosque}

En la región, $52.9 \%$ de las unidades de producción rural $\left(1^{\prime} 904,608\right)$ pertenecen al régimen de propiedad privada, ${ }^{17} 46.6 \%$ a la ejidal, $0.3 \%$ a la propiedad de colonia, $0.2 \%$ es comunal y 0.3\% pública (INEGI, 1994). N o obstante que el régimen de propiedad de la tierra, más allá de su condición jurídica, se constituye en un factor social que condiciona la forma en que los ejidatarios y comuneros aprovechan los recursos naturales (agua, suelo y vegetación), ${ }^{18}$ la manera en que se establece la relación entre ellos, el manejo del bosque, el deterioro y/o la conservación del recurso responde a factores de diversa índole, como los conflictos derivados de la incompatibilidad entre las reglas comunitarias y la legislación aplicable (agraria y ambiental), así como por las posibilidades o no de recibir apoyos y fomento externo y, por

${ }^{16}$ La Ley de Desarrollo Forestal Sustentable restringe el aprovechamiento del bosque por parte de los miembros de las comunidades, penaliza el uso doméstico de leña y limita el uso de otros productos del bosque a las ceremonias religiosas; se ha roto con la exclusividad de las comunidades forestales sobre el uso de sus recursos, provocando que los permisos de aprovechamiento se puedan transferir en operaciones mercantiles; la instalación de empresas comunitarias debe cumplir con los requisitos administrativos y técnicos que marca la reglamentación federal (plan de manejo, programa de explotación y toda clase de formatos administrativos), cuestiones todas ellas que han dejado fuera a la mayor parte de las comunidades forestales y con reducida posibilidad de capacitarse para la gestión adecuada de sus recursos forestales.

${ }^{17}$ La propiedad privada la constituyen los predios o terrenos que son transferibles a los particulares mediante venta, cesión o herencia y declarados en el Registro Público de la Propiedad. La propiedad ejidal se refiere a la superficie o tierras que usufructuan los núcleos de población campesina con posterioridad a la Ley Agraria del 6 de enero de 1915 (O rozco et al., 2004: 42).

${ }^{18}$ La mayoría de las comunidades rurales que poseen gran parte de los recursos naturales no tienen su origen en poblaciones indígenas, en su mayoría son asentamientos ejidales que tienen un sistema dual de derechos de propiedad; existen parcelas individuales en las que un ejidatario las utiliza de la manera que más les convenga; por otro lado existen terrenos de propiedad común, cuyo usufructo depende de las reglas de acceso establecidas por la comunidad (INE, 2000). 
supuesto, los conflictos internos producidos por la apropiación, el uso y el manejo de los recursos naturales. ${ }^{19}$

En la región se registran 2,091 propiedades sociales, 95.1\% tiene como actividad principal la agricultura, aunque la mayoría de los ejidos cuenta con superficie forestal, sólo $1.8 \%$ se dedica a la actividad forestal, $1.8 \%$ a la ganadería y $1.3 \%$ a otras actividades (INEGI, 1994). El 50\% de los ejidos forestales se ubican en el noreste de M ichoacán (Aporo, Hidalgo, Jungapeo, Senguio, Sususpuato, Tuzantla y Zinapécuaro).

En el ámbito de la explotación del bosque, se tienen desde comunidades rentistas que no real izan ninguna actividad de aprovechamiento y sólo venden su madera en pie a contratistas, hasta comunidades con diferentes niveles de integración vertical dentro de la actividad forestal (INE, 2000: 13).

El $69 \%$ de los ejidos y comunidades que explotan el bosque destinan la producción al autoconsumo y $31 \%$ a la venta local 0 nacional, las especies aprovechadas son el pino y el encino, en menor medida el oyamel y la leña es el producto de uso doméstico más importante.

La recolección de resina representa una alternativa importante en la economía de al gunas comunidades. El Bajío y noreste de M ichoacán cuentan con comunidades recolectoras en los municipio de $\mathrm{H}$ idalgo y Zinapécuaro, y en el Estado de M éxico se práctica la resinación del bosque en San Felipe del Progreso, D onato Guerra, Ixtapan del Oro y Tenancingo (figura Iv).

${ }^{19}$ El pueblo náhuatl de Santa Catarina del M onte, Texcoco, Estado de M éxico (González y Leal, 1993), expone el conflicto histórico entre las reglas comunitarias (derecho consuetudinario), la normatividad agraria y la joven normatividad ambiental que promueve su conservación y uso restringido (derecho positivo), en particular en las áreas naturales protegidas; la comunidad indígena de N uevo San Juan Parangaricutiro, M ichoacán (Bocco et al., 2000), es un caso de desarrollo comunitario sustentable donde el acompañamiento y la asesoría de agentes externos (gobierno e instancias académicas) han logrado establecer sinergias para fortalecer la organización comunitaria para aprovechar, diversificar y conservar los recursos naturales disponibles; el ejido de San N icolás Totolapan, delegación Tlalpan, Distrito Federal (Salazar, 2000), muestra la relación que los ejidatarios y comuneros, habitantes de un poblado de origen rural absorbido por la mancha urbana, tienen con los recursos naturales sobre los que mantienen derechos agrarios. Aquí la acción colectiva y la gestión comunitaria está mediada por la aplicación de la legislación agraria y ambiental que imposibilita una relación equilibrada entre los recursos y la población, los conflictos internos en el uso y manejo de los recursos naturales se manifiestan en identidades unidas a la permanencia de los recursos naturales e identidades construidas con base en valores y normas que rigen la vida urbana, como las transacciones por dinero y la lucha por el poder. 


\section{Figura IV \\ Participación de la superficie de bosque en la superficie ejidal y ejidos con actividad económica principal forestal}

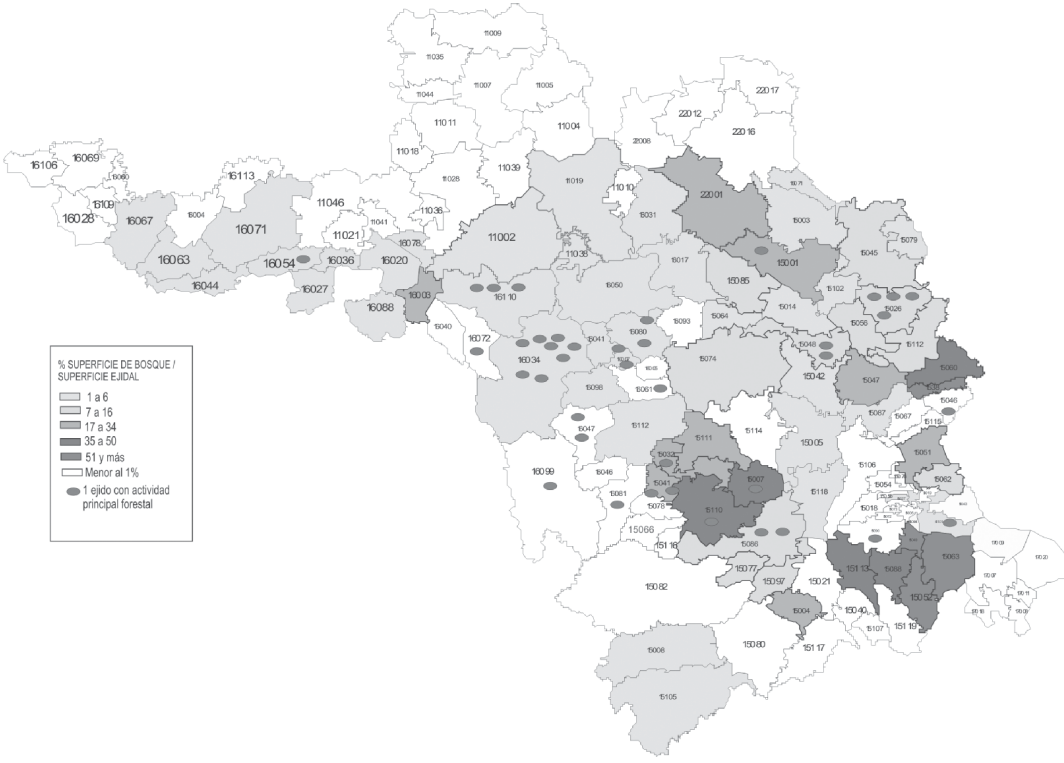

Fuente: INEGI (1994). Elaboración de M aría Estela O rozco H ernández.

El mayor número de ejidos en los que se explotan los bosques con fines comerciales se localizan en el noreste de M ichoacán. ${ }^{20}$ En esta zona se presentan casos de manejo forestal comunitario ${ }^{21}$ sostenido en una buena organización productiva y comercial. Aunque no existe un modelo de organización que asegure el éxito en el manejo de los recursos forestales; algunos elementos comunes entre los casos exitosos son: consolidación de un área de manejo forestal de mediana a grande, manejo comunitario del bosque, rendición de cuentas a la comunidad, combinación de varios niveles de organización, beneficios tangibles en el corto plazo, mecanismos claros de evaluación y control, así como reinversión de las ganancias, lo que da un proceso gradual de capitalización. Tales variables son difíciles de encontrar en todos los núcleos agrarios con bosque, de aquí que los casos exitosos de

${ }^{20}$ En M éxico son pocos los núcleos agrarios que se dedican a la actividad forestal maderable, a pesar de que casi $25 \%$ de la totalidad de núcleos agrarios cuenta con vegetación forestal. Dentro de estos núcleos son pocos los casos exitosos donde el manejo maderable de los recursos ha promovido el desarrollo de las comunidades y a la vez se ha conservado el recurso forestal (INE, 2000).

${ }^{21} \mathrm{H}$ idalgo, Zinapécuaro, J ungapeo, Q ueréndaro, Senguio. 
manejo forestal y buena conservación de los recursos es reducida (INE, 2000: 2). Los logros en los casos de manejo de forestería comunitaria no han erradicado algunas debilidades y adversidades, como el aumento de la migración y la disminución de los volúmenes aprovechables debido a la competencia con madera importada. Sin embargo, su éxito muestra que el camino para estabilizar la superficie forestal es lograr una producción sostenible y generar beneficios para la población local, lo cual depende de la participación ordenada de los propietarios y la creación del marco político e institucional para fortalecer las experiencias y conseguir que se generalicen como modelo de desarrollo forestal (Barton y M erino, 2004).

La relación entre la superficie de bosque y el uso del suelo en la propiedad social se establece a partir del aprovechamiento de la cobertura vegetal con fines económicos (uso del suelo). En la propiedad social las superficies agrícola y de pastizal contribuyen con $88 \%$ de la superficie total, en tanto que la forestal tiene un papel secundario, aporta 2'795,727.99 ha, es decir, 11\% de la superficie total (cuadro 3).

La expansión de la agricultura es un fenómeno regional de suma importancia para las economías estatales y municipales. El patrón de cultivos destaca el maíz como producto extensivo predominante y una variedad de cultivos cíclicos y perennes que demandan los mercados nacional e internacional (hortalizas). Frente a la importancia comercial de la producción agrícola de riego y temporal en el Bajío y noreste de M ichoacán, Guanajuato-Celaya y San Juan del Río se identifican áreas no representativas comercialmente, consideradas así debido a que su producción se dedica sobre todo al autoconsumo, como sucede en los municipios del Estado de M éxico (figura v).

En un estudio realizado por el Centro Empresarial del Asesoría, s. c., se estimaron los costos de oportunidad del uso del suelo forestal en ejidos del norte y centro de M éxico, su objetivo fue definir el monto del pago por servicios ambientales para que los propietarios conserven el bosque (INE, 2002). N o obstante que los resultados demostraron la limitada productividad y rentabilidad de la agricultura y la ganadería extensiva en zonas forestales, la expansión de superficie dedicada a estas actividades económicas no tiene más límite que las necesidades de supervivencia de los ejidatarios y comuneros, los cuales adoptan pautas de manejo que afectan negativamente los suelos, el agua y la vegetación. 


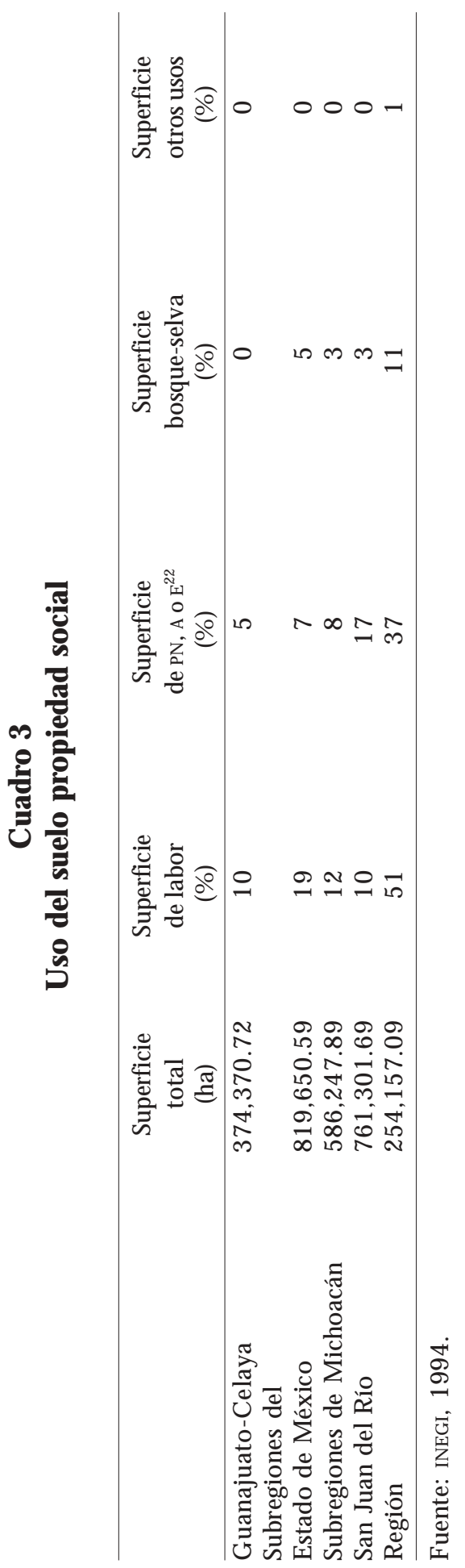




\section{Figura $v$ \\ Patrón de cultivos ciclícos y perennes}

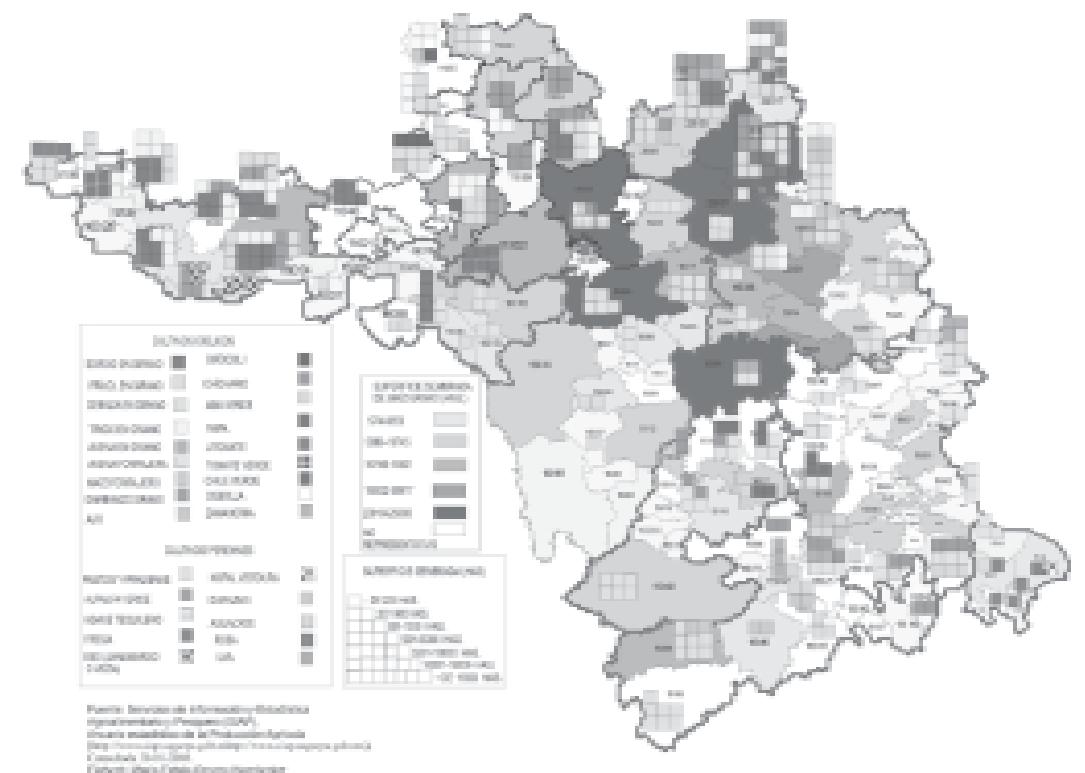

Fuente: http://siap.sagarpa.gob.mhtpp://www.ciap.sagarpa.gob.mx. Elaboración de M aría Estela O rozco Hernández.

El resultado inmediato del avance de la frontera agropecuaria es el cambio de uso de suelo, cuyos efectos colaterales inducen la alteración del ciclo hidrológico, la aceleración de la erosión, la pérdida de biodiversidad y cambios climáticos, entre otros. El cambio de uso de suelo con fines agropecuarios se agudiza en las áreas limítrofes de los estados de M éxico y M ichoacán, lo que implica la perturbación, la pérdida de bosque, ${ }^{23}$ la transformación del paisaje y las funciones ambiental y económica del ecosistema original.

Entre otros aspectos, la topografía y los suelos de vocación forestal limitan el desarrollo adecuado de la agricultura y en consecuencia presentan una elevada susceptibilidad a la erosión, con ella se pierde la productividad y se agota rápidamente la fertili-

${ }^{23}$ El Inventario Nacional de Uso de la Tierra de 2000 -realizado por la UnAM y financiado por el INEGI y la Semarnap- encontró que las pérdidas forestales en el periodo 1976-2000 fueron de $0.25 \%$ para los bosques templados y $0.76 \%$ para los bosques tropicales, lo cual implica una perdida anual de 86,718 ha y de 263,570 ha, respectivamente, que suman una pérdida total de 350,288 ha. En este estudio se confirma que las tasas de deforestación en áreas tropicales han sido mucho más altas que en zonas templadas (Barton y M erino, 2004: 1-26). 
dad de los suelos, ocasionando efectos negativos a la producción y al productor.

La relación satisfacción de necesidades de subsistencia-avance de la frontera agropecuaria-cambio de uso del suelo-pérdida de la cubierta forestal-rendimientos agrícolas decrecientes determina un círculo vicioso que parte de la pobreza rural, sigue con la degradación de los recursos forestales y cierra con más pobreza rural. ${ }^{24} \mathrm{En}$ este contexto se vislumbra que la pobreza es un factor de circularidad -el pobre será cada vez más pobre- que deviene de la satisfacción inmediata de las necesidades básicas, por ejemplo, cuando se tiene que el egir entre proyectos alternativos, la situación de pobreza fomentará que se escoja aquél con mayores rendimientos a corto plazo, como optar por el cultivo de maíz o la ganadería en lugar de destinar la tierra a la silvicultura. Esto sucede porque los proyectos ambientales relacionados con el bosque generan beneficios de largo plazo (INE, 2000: 4).

0 tro elemento que propicia el empobrecimiento de los bosques es la ambigüedad en los derechos y los límites imprecisos de la propiedad sobre los recursos forestales. Los conflictos por la tenencia de la tierra afectan la superficie boscosa del noreste de M ichoacán, Valle de Bravo y sur del Estado de M éxico, las ocupaciones ilegales de territorios boscosos que están bajo resguardo del gobierno (RBM м y otras áreas naturales protegidas) siguen mostrando el problema de aprovechamiento ilegal e irracional de los bosques. En el fondo de este asunto se encuentra la escasa inversión en vigilancia y el desinterés por parte de los ejidatarios y comuneros para cuidar un recurso natural ubicado en áreas de uso comunitario que no les reporta beneficios inmediatos. Esto se atribuye a problemas de coordinación y organización que no permiten incentivar proyectos alternativos que beneficien a las comunidades, pues cuando se logra cierto nivel de organización para el aprovechamiento de los bosques, en muchas ocasiones se presenta corrupción y una desigual distribución de los beneficios, fricción social y pérdida de credibilidad, y como consecuencia se debilita el control social en el uso de los recursos forestales (INE, 2000: 10).

\footnotetext{
${ }^{24}$ Debido a que los pobres se encuentran en la urgencia por conseguir satisfactores básicos para sobrevivir, el valor relativo del consumo presente respecto al consumo futuro es muy grande. Cuando aquellas comunidades pobres tienen acceso a algún recurso natural, tenderán a extraerlo más rápidamente, tal vez llevándolo a su agotamiento, ya que el recurso valdrá más consumido que si se deja en su sitio creciendo en valor (INE, 2000: 4).
} 


\section{Balance del aprovechamiento del bosque}

Los resultados de esta investigación muestran el estado que guarda el aprovechamiento del bosque en la región interestatal del Lerma, así como una aproximación a las causas y consecuencias del deterioro del bosque.

Los aspectos que envuelve la dinámica de explotación del bosque son: la heterogeneidad social y económica de la región, la concentración urbana y una alta dispersión de la población rural, la excesiva expansión de la frontera agropecuaria, el acelerado crecimiento industrial y de servicios, el bajo costo de la tierra, el deterioro y pérdida de los suelos y la contaminación de aguas de origen agropecuario y urbano.

Los factores de presión que afectan las cubiertas y las funciones ambientales del bosque, en orden de importancia, son el avance de la frontera agropecuaria, los incendios inducidos que se constituyen en un medio para propiciar el cambio de uso del suelo, la tala clandestina y el aprovechamiento industrial de la madera y sus derivados.

La degradación del bosque, la deforestación y los cambios de uso del suelo se manifiestan como expresiones socioculturales, económicas y políticas resultado de las actividades de aprovechamiento de múltiples participantes que ejercen presión sobre los bosques y que también son causantes de los procesos de deterioro (ejidatarios, comuneros, industriales, el gobierno en todos sus niveles y los traficantes ilegales).

$\mathrm{N}$ o obstante que en años recientes se actualizaron y promulgaron nuevas leyes y reglamentos federal es que inciden directa 0 indirectamente en la regulación del aprovechamiento de los recursos forestales, contienen disposiciones confusas y contradictorias que dan mayor importancia a la protección y la conservación del recurso, pero que no consideran las necesidades de las comunidades rurales; paralelamente se genera un exceso de trámites burocráticos para llevar a cabo una actividad económica determinada, en consecuencia, la actividad forestal legal se ha inhibido pero no se ha logrado mitigar la tala clandestina y el deterioro ambiental asociado a la deforestación.

El balance sintético de la situación se expone mediante un sistema de retroalimentación que se rige por la función principal de la apropiación social de la sostenibilidad como base del aprovechamiento y conservación del bosque, su objetivo se orienta hacia el beneficio de la población local y al impulso del desarro- 
Ilo rural. La determinación de las fortalezas, oportunidades, debilidades y amenazas (FODA) ${ }^{25}$ expone en un solo plano los factores internos y externos que favorecen o limitan el aprovechamiento sustentable de los recursos forestales, y con base en ello se proponen algunas pautas de atención para impulsar el desarrollo rural (cuadro 4). Los objetivos de las estrategias de aprovechamiento (Fo) son mantener la vocación del suelo y reducir la pérdida de la superficie forestal; las estrategias de fortalecimiento (Do) pretenden mitigar el avance de la frontera agropecuaria y el desmonte; las estrategias de defensa (DA) contemplan las necesidades básicas de los miembros de las comunidades para usar sus recursos naturales de manera regulada y desarrollar formas locales de empleo acordes con su contexto social, cultural y ambiental; las estrategias de defensa agresiva (FA) se orientan a la creación de mecanismos que aminoren los efectos de las externalidades y favorezcan el desarrollo comunitario. Las distintas líneas generales de orientación y coordinación de las acciones deberán estar cohesionadas por políticas de intervención que garanticen su cumplimiento.

Políticas de aprovechamiento. Para implementar acciones 0 proyectos es necesario realizar estudios de factibilidad que contengan los elementos técnicos, sociales y económicos que garanticen su viabilidad y la evaluación de los resultados. El pago por servicios ambientales deberá definir un sistema de distribución que permita garantizar montos específicos de apoyo destinados a la mejora de los servicios y el equipamiento de cada comunidad. Fortalecer la conciencia ambiental colectiva mediante apoyos que beneficien el desarrollo social comunitario.

Políticas de fortalecimiento. Garantizar que el área ocupada por las actividades agropecuarias no rebase umbrales mínimos de conservación y protección de la cubierta forestal. Abatir la incidencia de incendios y desmonte con fines económicos por medio de la regulación de su periodicidad y la definición de la superficie permitida.

${ }^{25}$ El análisis FODA es una técnica cualitativa que se utiliza como herramienta para el ordenamiento territorial, permite identificar las fortalezas y debilidades que expresarán las potencialidades y limitaciones internas de un territorio dado, así como las amenazas y oportunidades que perfilan el contexto exterior, estas últimas refieren aspectos coyunturales cambiantes que pueden influir positiva o negativamente en el territorio o en la problemática analizada. El cruce de las condiciones internas y externas orientará la definición de las estrategias y las políticas de acción (Pujadas y Font, 1998: 38; Gómez, 2002: 367; O rozco y Peña, 2004: 110). 


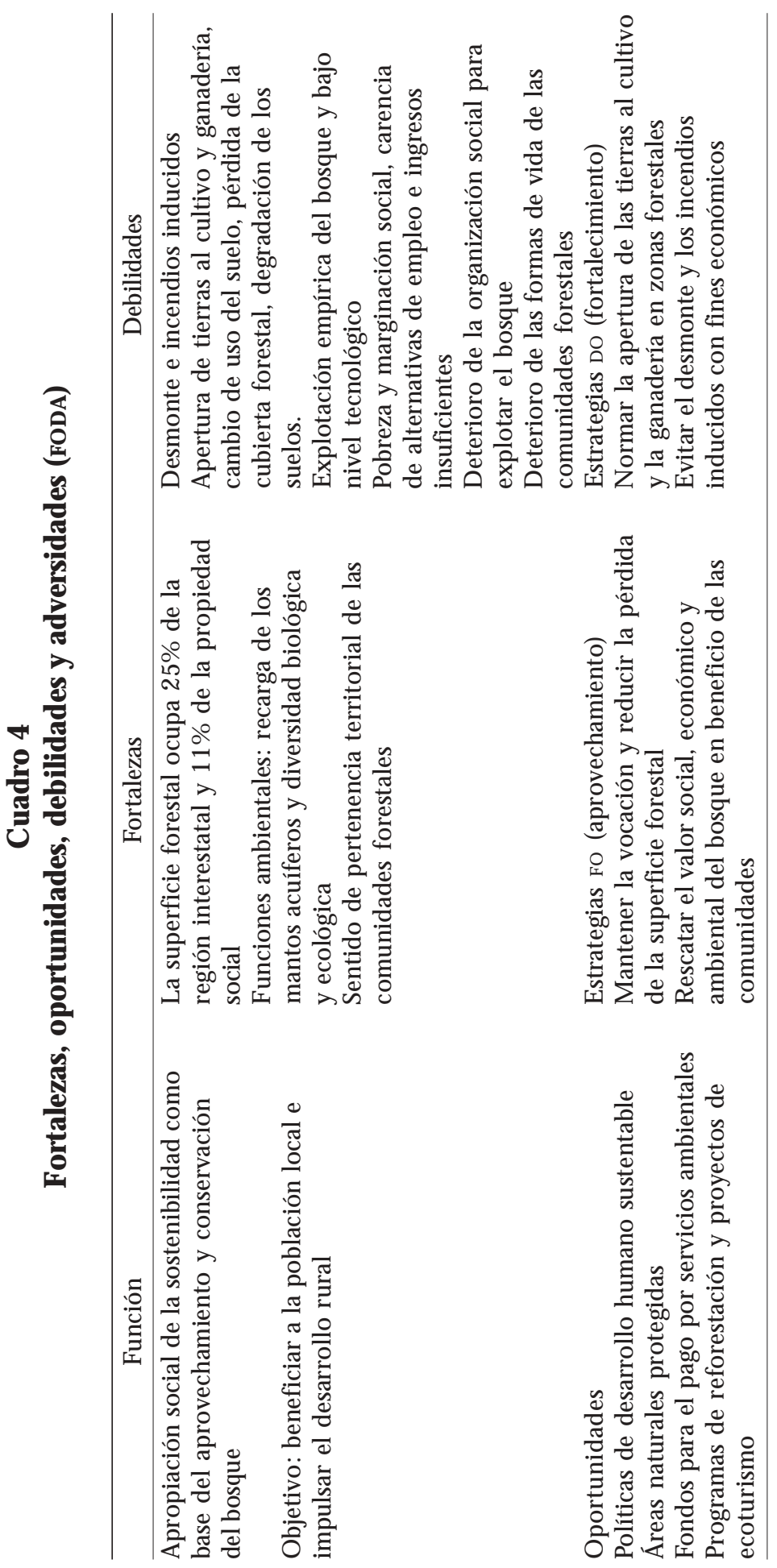




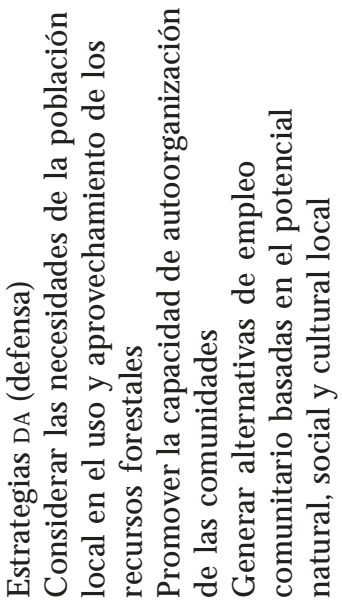

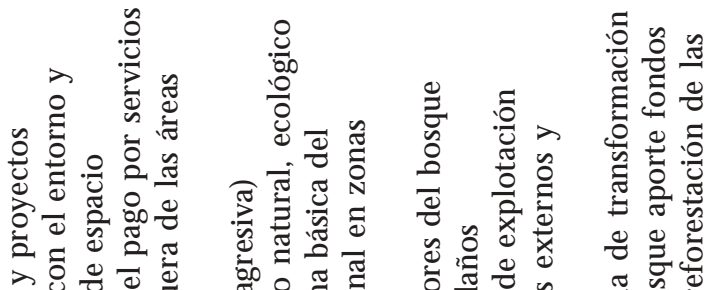

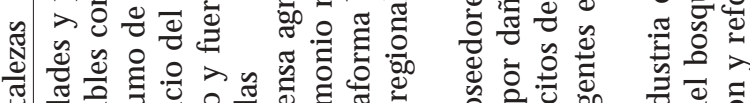

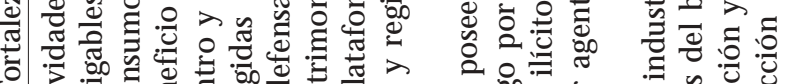
ㄴ.

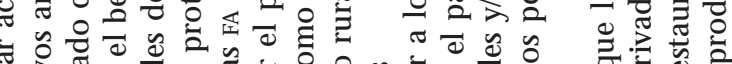

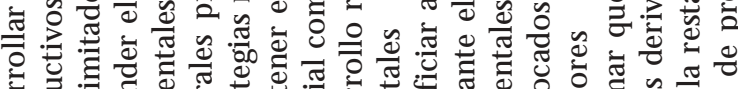

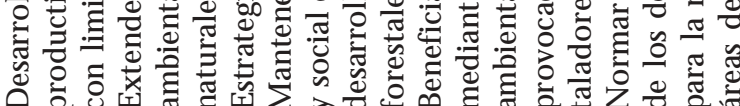

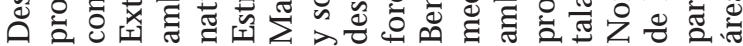
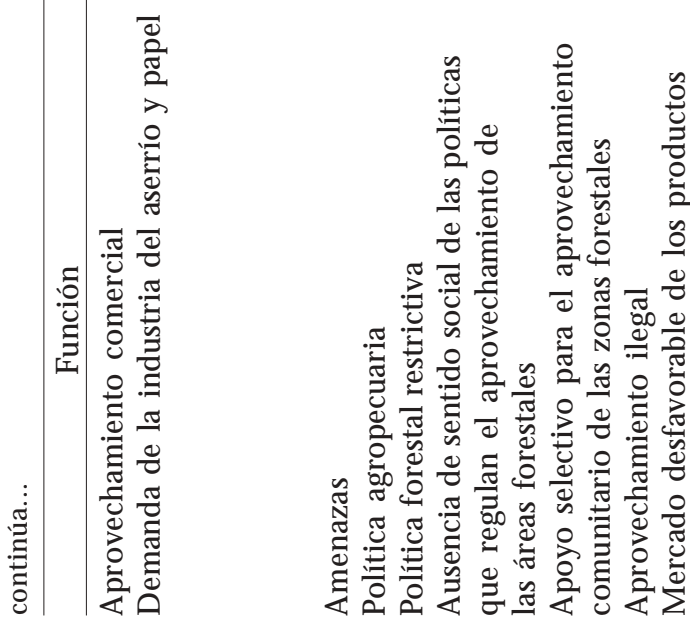

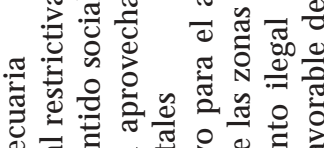
西

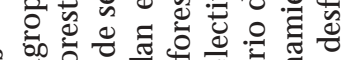


Políticas de defensa. Establecer cuotas de consumo familiar y comunitario con fines domésticos y comerciales de pequeña escala, acorde con la definición de superficies forestales afectables y establecer compromisos de trabajo para su restauración y/o recuperación. Asignar apoyos federales y estatales que permitan preparar recursos humanos locales como base de la organización endógena. Promover el intercambio complementario entre las comunidades forestales y el intercambio hacia el exterior para favorecer economías de escala y socializar los riesgos del deterioro y la pérdida de la cubierta forestal

Políticas de defensa agresiva. Respetar los derechos de propiedad de los ejidos y comunidades agrarias e incrementar los apoyos gubernamentales para aprovechar, prevenir, conservar y restaurar el bosque. Determinar el pago por daños ambientales en efectivo o en especie provocados por los operadores de la tala clandestina y los agentes externos. Crear fondos empresariales para la restauración y reforestación de las áreas de producción.

\section{Consideraciones finales}

En la medida que la disponibilidad de los recursos naturales tiene un efecto en la calidad de vida de las sociedades presentes y futuras, la definición del marco político que regula su aprovechamiento en M éxico pretende conciliar las metas del crecimiento económico con la conservación de la naturaleza. La implementación de medidas correctivas soslaya las medidas preventivas y coloca el desarrollo rural como una consecuencia, cuando es precisamente en las capacidades de organización, autodeterminación, empoderamiento y conocimiento de las personas y las comunidades en las que se encuentra la posibilidad de lograr efectivamente el desarrollo.

Lo anterior se aprecia en las disposiciones emanadas de la Ley de Desarrollo Rural Sustentable (Dof, 2001), en la cual es prioridad el mejoramiento integral del bienestar social de la población y de las actividades económicas en el territorio no urbano, sin menoscabo de los recursos naturales, la biodiversidad y los servicios ambientales. Según se apunta, los mecanismos para promover el desarrollo rural sustentable son atribuciones del Estado mediante la inversión en infraestructura y apoyos directos a los productores para incrementar la eficiencia de sus unidades de producción, mejorar sus ingresos y fortalecer su competitividad. Frente a la perspectiva productiva y económica del desarrollo, la Ley de Desarrollo Forestal Sustentable (DoF, 2003) 
aparece como un instrumento de política tecnócrata que regula y sanciona las acciones de manejo y aprovechamiento de los ecosistemas forestales del país, así como su conservación, protección y restauración, pero que no toma en cuenta la participación proactiva de los poseedores de los recursos naturales y no ha logrado detener las tendencias de su deterioro.

Es una tarea prioritaria analizar el grado de coherencia entre los diversos instrumentos que conforman el marco legal general que regula el aprovechamiento de los recursos forestales, así como los arreglos e instituciones locales que determinan el uso del bosque y la tierra en las comunidades forestales. La mayor atención que se ha dado a la solución de las consecuencias del deterioro del bosque, limita la definición de mecanismos para dar solución a las causas, por lo que es necesario un cambio de enfoque que permita repensar las formas de intervención gubernamental y las oriente hacia la definición de mecanismos que fortalezcan la conciencia ambiental de las comunidades forestales, para con ello lograr la apropiación social de la sustentabilidad como base del desarrollo rural y regional de largo plazo. De no considerar estos aspectos, se estaría frenando la posibilidad de aprovechar las oportunidades y fortalezas de las zonas forestales en el marco de una política económica adversa que cuestiona toda forma de desarrollo rural.

\section{Agradecimientos}

Contamos con el apoyo de la Universidad Autónoma del Estado de $\mathrm{M}$ éxico y el Consejo $\mathrm{N}$ acional de Ciencia y Tecnología mediante los proyectos Uaemex 2050/2005, Conacyt-Semarnat 200201430 y Conacyt 200754706.

\section{Bibliografía}

Alburquerque, Francisco (2001), "Ajuste estructural e iniciativa de desarrollo local", Comercio Exterior, 51 (8), M éxico, p. 675.

Ávila Curiel, Abelardo, Carlos Galindo Gómez y Adolfo Chávez Villasana (2005), Encuesta Nacional de Alimentación y Nutrición en el Medio Rural. Estado de México, Instituto $\mathrm{N}$ acional de Ciencias M édicas y Nutrición Salvador Zubirán-Difem, Toluca, M éxico. 
Barton Bray, David y Leticia M erino Pérez (2004), La experiencia de las comunidades forestales en M éxico, INE-Semarnat, $M$ éxico.

Bassols Batalla, Ángel (1983), México, formación de regiones económicas. Influencias, factores y sistemas, Universidad $\mathrm{N}$ acional Autónoma de $\mathrm{M}$ éxico, $\mathrm{M}$ éxico.

Bermejo, Roberto (2000), "Acerca de dos visiones antagónicas de la sostenibilidad", en Iñaki Bárcena, Pedro Ibarra y $M$ ario Subyaga (coords.), Desarrollo sostenible: un concepto polémico, Servicio Editorial Universidad País Vasco, Zaratauz, pp. 67-103.

Bocco, Gerardo, Alejandro Velázquez y Alejandro Torres (2000) "Ciencia, comunidades indígenas y manejo de recursos naturales. Un caso de investigación participativa en M éxico", Interciencia, 25 (2), Asociación Interciencia, Caracas, pp. 64-70.

Challenger, Antony (2004), "Los ecosistemas templados de M éxico", Seminario Desarrollo sustentable y ecosistemas templados de Durango, 6 de agosto, Dirección de la Reserva de la Biosfera La M ichilía-Conanp-Semarnat, Durango, M éxico, http://www.cybertechnics.com.mx/conanp/ noticia. php? $\mathrm{N}$ otiL eer $=1 \&$ TitBack $=3 \&$ IdN otic $=81$.

Conafor (Comisión N acional Forestal) (2006), Datos a los bosques. N úmero de incendios forestales, Gerencia de Incendios Forestales, M éxico, D.F. http://148.223.105.188: $2222 / \mathrm{gif} / \mathrm{sni} / \% 5 \mathrm{fportal} / \mathrm{index}$.php?option $=\mathrm{com}$ content\& task $=$ view $\&$ id $=51 \&$ itemid $=65$.

Conanp (Comisión Nacional de Áreas $\mathrm{N}$ aturales Protegidas) (2005), Áreas Naturales de México, Semarnat, M éxico. http://www.conanp.gob.mx/anp.doc, consultado el 30 de abril de 2008.

DoF (Diario O ficial de la Federación) (2001), “Ley de Desarrollo Rural Sustentable", publicada 7 de diciembre, Cámara de Diputados del H. Congreso de la Unión, http:// www.diputados.gob.mx/LeyesBiblio/, 7 de mayo de 2008. 
DoF (Diario Oficial de la Federación) (2003), “Ley General de Desarrollo Forestal Sustentable", publicada 25 de febrero, Cámara de Diputados del H . Congreso de la Unión, http:/ /www.diputados.gob.mx/LeyesBiblio/, 7 de mayo de 2008.

DoF (Diario O ficial dela Federación) (2006), N orma O ficial M exicana N O M -026-SEM AR N AT-2005, que establece los criterios y especificaciones técnicas para el aprovechamiento comercial de la resina de pino, 28 de septiembre, Cámara de Diputados del H . Congreso de la Unión, http:/ /www.diputados.gob.mx/LeyesBiblio/, 7 de mayo de 2008.

G-Bosques (2006) "Llamado del Grupo Bosques (G-Bosques), Rumbo Rural, año 1, 3, cEDRSSA, M éxico, pp. 63-73. http:// www.ccmss.org. mx/modulos/biblioteca_consultar. php?folio $=124$.

Gerritsen, Peter R. W., M aría M ontero y Pedro Figueroa (2003), "El mundo en un espejo. Percepciones campesinas de los cambios ambientales en el occidente de M éxico", Economía, Sociedad y Territorio, vı (14), El Colegio M exiquense, Toluca, pp. 253-278.

Gobierno Federal de los Estados Unidos M exicanos (2007), Plan Nacional de Desarrollo 2007-2012, Presidencia de la República, M éxico, http://pnd.presidencia.gob.mx/.

Gómez O rea, Domingo (2002), O rdenación territorial, M undiPrensa, M adrid.

González, José y Regina Leal (1993), “M anejo de recursos naturales y derecho consuetudinario, Revista Nueva Antropología, XIII (44), N ueva Antropología, A.c., M éxico, pp. 61-70.

INE (Instituto N acional de Ecología) (2000), "Situación general existente en las comunidades agrarias con respecto al manejo de los recursos naturales", www.ine.gob.mx/dgipea/descargas/ejido_conserv_3.pdf, 1 de mayo de 2008.

INE (Instituto N acional de Ecología) (2002), Estimación del costo de oportunidad del uso del suelo forestal a nivel nacional, Semarnat, M éxico. 
INEGI (Instituto N acional de Estadística, G eografía e Informática) (1984), Cartas de vegetación y uso del suelo: E 14-1 (M orelia), F14-11 (H idalgo) y E14-2 (Ciudad de M éxico), escala 1:250,000, INEGI, Aguascalientes, M éxico.

INEGI (Instituto N acional de Estadística, G eografía e Informática) (1989), Carta de vegetación y uso del suelo F14-10 (Q uerétaro), escala 1:250,000, INEGI, Aguascalientes, M éxico.

INEGI (Instituto N acional de Estadística, G eografía e Informática) (1992), Carta de vegetación y uso del suelo F14-7 (Guanajuato), escala 1:250,000, INEGI, Aguascalientes, M éxico.

INEGI (Instituto N acional de Estadística, G eografía e Informática) (1994), Consulta electrónica de tabulados. Resultados Definitivos VII Censo Agrícola Ganadero y Ejidal, INEGI, M éxico.

INEGI (Instituto N acional de Estadística, Geografía e Informática (1997), "Anuarios estadísticos de M éxico, M ichoacán, Guanajuato y Querétaro, http://www.inegi.gob.mx/lib/ buscador/busqueda. aspx?s= inegi $\&$ textoBus= anuarios $\%$ 20 estadísticos $\% 20 \&$ e= $\&$ seccionBus= docit.

INEGI (Instituto N acional de Estadística, G eografía e Informática) (2000), Tabulados básicos nacionales y por entidad federativa. Base de datos y tabulados de la muestra censal. XII Censo General de Población y Vivienda, 2000, Aguascalientes, M éxico.

INEGI (Instituto N acional de Estadística, G eografía e Informática) (2004), Tabulados básicos de los Censos Económicos 2003, M éxico. [http://www.inegi.gob.mx, 20 de septiembre de 2005.

M artínez Piva, Jorge M ario (2001), “El desarrollo local en América Latina", Comercio Exterior, 51 (8), M éxico, p. 683.

M éndez D elgado, Elier y M aría del Carmen Lloret Feijóo (2001), "Procedimiento para medir el desarrollo económico local en Cuba", Comercio Exterior, 51 (8), M éxico, pp. 718-725. 
M orán Villaseñor, José Antonio y H ugo Galletti Busi (2002), Causas económicas e incidencias del comercio internacional en la deforestación en México, Centro M exicano de Derecho Ambiental, A.c., M éxico.

M uñoz Piña, C arlos (2004), Subsidios agrícolas en M éxico que tienen efectos ambientales negativos, IN E-Semarnat, M éxico.

O rozco Hernández, M aría Estela y Vicente Peña $M$ anjarrez (2004), "Evaluación diagnóstica para el ordenamiento territorial de la Cuenca Alta del Río Lerma", Actas Latinoamericanas de Varsovia, tomo 27, Universidad de Varsovia, Varsovia, pp.107-120.

O rozco H ernández, M aría Estela, Vicente Peña M anjarrez, Roberto Franco Plata y N oel Bonfilio Pineda Jaimes (2004), Atlas agrario ejidal del Estado de México, Universidad Autónoma del Estado de M éxico, Toluca, M éxico.

O rozco Hernández, M aría Estela y M aría del Rosario Canales Vega (2007), "Fundamentos para el estudio del desarrollo local rural", en Jorge Tapia Q uevedo y M iroslawa C zerny (coords.), Territorio y sociedad. La dimensión de los agentes actuantes, Universidad Autónoma del Estado de M éxico-Universidad de Varsovia, Toluca, M éxico, pp. 306-327.

PNUd (United N ations Development Programme) (2003), H uman D evelopment Report 2003, M illenium Development GoaIs, A compact Amoung $\mathrm{N}$ ations to the end $\mathrm{H}$ uman Poverty, N ew York, Oxford University Press, http://hdr.undp.org/ en/media/hdr03_complete.pdf, consulta 30 de abril del 2008.

Pujadas, Romá y J aume Font (1998), O rdenación y planificación del territorio, Síntesis, M adrid.

Ramírez Ramírez, Isabel (2001), "Cambios en las cubiertas del suelo en la sierra de Angangueo, M ichoacán y Estado de M éxico. 1971-1994-2000", Investigaciones Geográficas, Boletín del Instituto de Geografía, 45, Universidad Nacional Autónoma de M éxico, M éxico, pp. 39-55. 
Rofman Alejandro Boris (1993), "Redefinición del elemento clave del análisis espacial: la región", en H éctor Ávila Sánchez (comp.), Lecturas de análisis regional en México y América L atina, Universidad Autónoma Chapingo, M éxico, pp. 239-261.

Rzedowski, Jerzy (1983), La vegetación de México, Limusa, M éxico.

Salazar Cruz, Clara (2000), "La relación de la población y los recursos naturales en un área de expansión de la ciudad de M éxico (Parte B)", Estudios Demográficos y Urbanos, 44, El Colegio de M éxico, M éxico, pp. 287-324.

Semarnap (Secretaría de M edio Ambiente, Recursos N aturales y Pesca) (1998), Información estadística de incendios en áreas forestales por entidad federativa: Informe final, Semarnap, M éxico.

Semarnap (Secretaría de M edio Ambiente, Recursos N aturales y Pesca) (2000), Guía forestal, Semarnap, M éxico.

Semarnat (Secretaría de M edio Ambiente y Recursos $\mathrm{N}$ aturales) (2003), Compendio de Estadísticas Ambientales 2002, Superficie forestal por ecosistema y tipo de vegetación, Subsecretaría de Gestión para Protección Ambiental, Dirección General de Gestión Forestal y de Suelos, M éxico, D.F. http://www.semarnat.gob.mx/informacionambiental/documents/sniarn/estadistica/otros.html.

STPS (Secretaría del Trabajo y Previsión Social) (2005), Salarios mínimos vigentes a partir del $1^{\circ}$ de enero de 2006, Comisión N acional de Salarios M ínimos, M éxico.

Toledo, Carlos y Armando Bartra (eds.) (2000), Del círculo vicioso al círculo virtuoso. Cinco miradas al desarrollo sustentable de las regiones marginadas, Plaza y Valdés, M éxico.

Unikel Luis (1978), El desarrollo urbano de México: diagnóstico e implicaciones futuras, El Colegio de M éxico, M éxico. 
wwF (World Wide Fund for N ature) (2004), "Se documenta tala en la Región M ariposa M onarca", http://www.wwf. org.mx/wwfmex/archivos/bm/040601_documenTala M onrca.php, 15 de diciembre de 2007.

Recibido: 26 de mayo de 2008. Reenviado: 14 de octubre de 2008. Aceptado: 17 de noviembre de 2008.

M aría Estela 0 rozco $\mathrm{H}$ ernández. Es doctora en geografía. Actualmente se encuentra adscrita a la Facultad de Planeación Urbana y R egional de la Universidad Autónoma del Estado de M éxico. Es profesora-investigadora de tiempo completo, categoría D, docente en la maestría de Estudios Urbanos y Regionales; y en la licenciatura, maestría y doctorado en Ciencias Ambientales. Su línea de investigación actual se centra en estudios regionales y urbano-rurales. Entre sus publicaciones destacan: "Entre la competitividad local y la competitividad global: floricultura comercial en el Estado de M éxico", Convergencia, 14 (45), Universidad Autónoma del Estado de M éxico, Toluca, pp. 111-160 (2007); “Estrategia de supervivencia familiar en una comunidad rural del Estado de M éxico", Ciencia ergo sum, 14 (3), Universidad Autónoma del Estado de M éxico, pp. 246-254, (2007); "Cambio de ocupación de la población en núcleos agrarios ejidales del área perimetropolitana de la ciudad de Toluca, M éxico", en M aría Skoczek (coord.), Patrones de comportamientos socioeconómicos a nivel local en M éxico, Universidad de Varsovia, pp. 55-73 (2007); en coautoría, "Caracterización biofísica y social del Centro Ceremonial O tomí-M exica, Estado de M éxico" Quivera, 9 (2), Universidad Autónoma del Estado de M éxico, Toluca, pp. 207-221 (2007); en coautoría, "Competitividad local de la horticultura en Santa M aría Jajalpa, municipio de Tenango del Valle, Estado de M éxico" Q uivera, 9 (1), Universidad Autónoma del Estado de M éxico, Toluca, pp. 207-221 (2007).

Gabriela G utiérrez M artínez. Es licenciada en ciencias ambientales. Se desempeño como becaria del proyecto Uaemex 2050/ 2005 y colaboró en la sección "Espacio rural" en el proyecto Conacyt-Semarnat 2002 01430. Es egresada de la Facultad de Planeación Urbana y Regional de la Universidad Autónoma del Esta- 
do de M éxico. Ha publicado Diagnóstico ambiental del aprovechamiento del bosque templado en la región interestatal del alto Lerma (Estado de M éxico, Michoacán, Querétaro y Guanajuato), tesis de licenciatura, Universidad Autónoma del Estado de M éxico, Toluca (2006).

Javier D elgado Campos. Es doctor en urbanismo. Actualmente se encuentra adscrito al Departamento de Geografía Social, Instituto de Geografía de la Universidad N acional Autónoma de M éxico. Es investigador titular "A" de tiempo completo. Sus principales líneas de investigación son: estructura urbana y regional, sistema urbano nacional, interfase urbano-regional. Entre sus publicaciones destacan: "La urbanización difusa, arquetipo territorial de la ciudad región", Revista Sociológica, año 18, 51, Universidad Autónoma M etropolitana, Azcapotzalco, M éxico, pp. 13-48 (2003); en coautoría, "Del determinismo geográfico al espacio social, el caso del consumo urbano del agua", en A. Sánchez (coord.), M éxico en su unidad y diversidad territorial, tomo ॥, Instituto de Geografía-Sociedad M exicana de Geografía y Estadística, M éxico, pp. 393-409 (2002), en coautoría "Transición rural-urbana y oposición campo-ciudad", en A. G. A guilar (coord.), Urbanización, cambio tecnológico y costo social, Instituto de Geografía-ConacytM iguel Ángel Porrúa, M éxico, pp. 73-118 (2002). 